\title{
Symptomatic Gartner Duct Cyst in A Newborn: Diagnosis and Management
}

\author{
Warchol Stanislaw ${ }^{1 *}$, Rzewnicka Iwona ${ }^{1}$, BombinskiPrzemyslaw ${ }^{2}$ and Dudek-WarcholTeresa ${ }^{1}$ \\ ${ }^{1}$ Department of Pediatric Surgery and Urology, Medical University of Warsaw, Poland \\ ${ }^{2}$ Department of Pediatric Radiology, Medical University of Warsaw, Poland
}

Submission: April 01, 2017; Published: May 15, 2017

*Corresponding author: Warchol Stanislaw, Department of Pediatric Surgery and Urology, Medical University of Warsaw, Poland, Tel: +48 606 189 852; Email: swarchol@poczta.onet.pl

\begin{abstract}
Persistent Gartner Duct cyst is extremely rare in infants. We describe the case of Gartner Duct cyst with ectopic ureteral opening into the cyst and ipsilateral, non-functioning, dysplastic kidney, presenting initially as a large, inter labial cyst causing bladder empting problems and present its management.

Keywords: Gartner Duct Cyst; Interlabial mass; Mesonephric duct; Dysplastic kidney
\end{abstract}

\section{Introduction}

Persistent Gartner Duct cyst (GDC) with ectopicureteral opening and ipsilateral renal dysplasia is extremely rare in infants, and especially in newborns. Only a few reports describe this condition in infants [1-4].

\section{Case Report}

2-day old female was admitted from the Neonatological Unit because of vaginal mass causing bladder empting difficulties. On physical examinational large cystic mass at the introitus was present with urethral orifice displacement (Figure 1). Ultrasound (US) showed small, dysplastic right kidney, cystic mass between bladder and vagina and dilated distal ureter (Figure 2). Cystoscopy showed normally located left ureteral orifice, elevated left hemi-trig one and no right orifice within the bladder. No ectopic right ureteral orifice was found. Vaginoscopy showed cystic mass arising from the right vaginal wall. The cyst was incised, with clear fluid obtained (Figure 3). Further endoscopic examination of the resulted duct revealed dilated, tubular structure without visible end. Contrast study showed dilated, tortuous right ureter (Figure 4). Following incision, the cyst resolved and the newborn micturated without any problems. Normal bladder and urethra with no reflux was seen on voiding cystourethrography. Radionuclide scan revealed no function of the right kidney. Finally the diagnosis of persistent GDC with insertion of ectopic ureter based on the presence of vaginal cyst, the absence of the right ureteral orifice, communication of the cyst with the right ureter and dysplastic kidney, was
established(Figure 5). During one-year follow-up no voiding problems, no urinary tract infections were observed. Control US showed progressive decline of the right kidney.

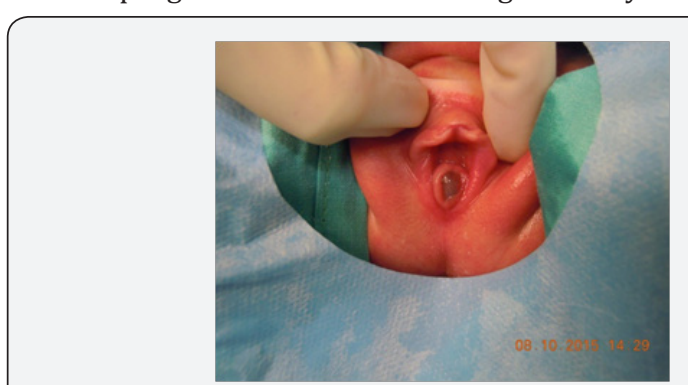

Figure 1: Large, interlabial mass in a female newborn.

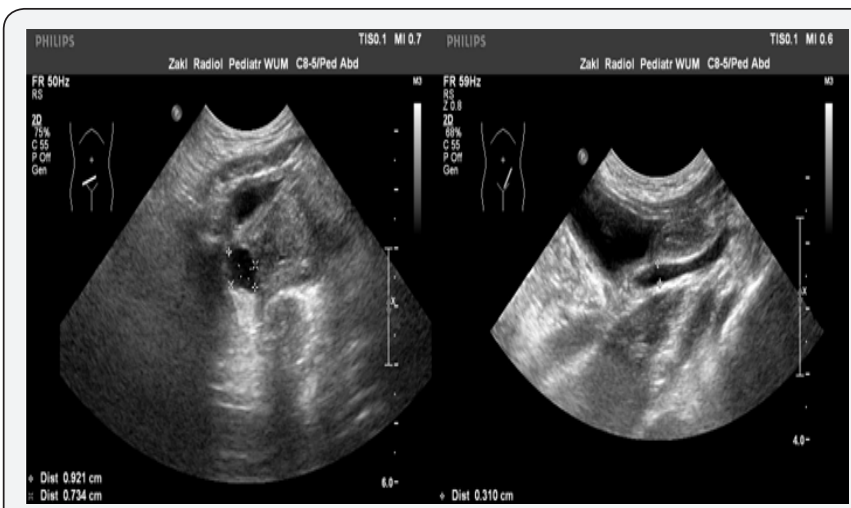

Figure 2: Ultrasound examination: cystic mass between bladder and vagina, dilated ureter. 


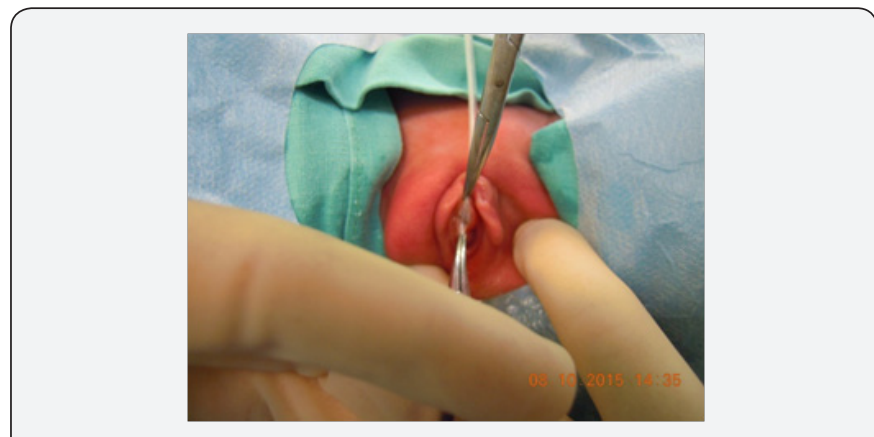

Figure 3: Incision of the cyst.
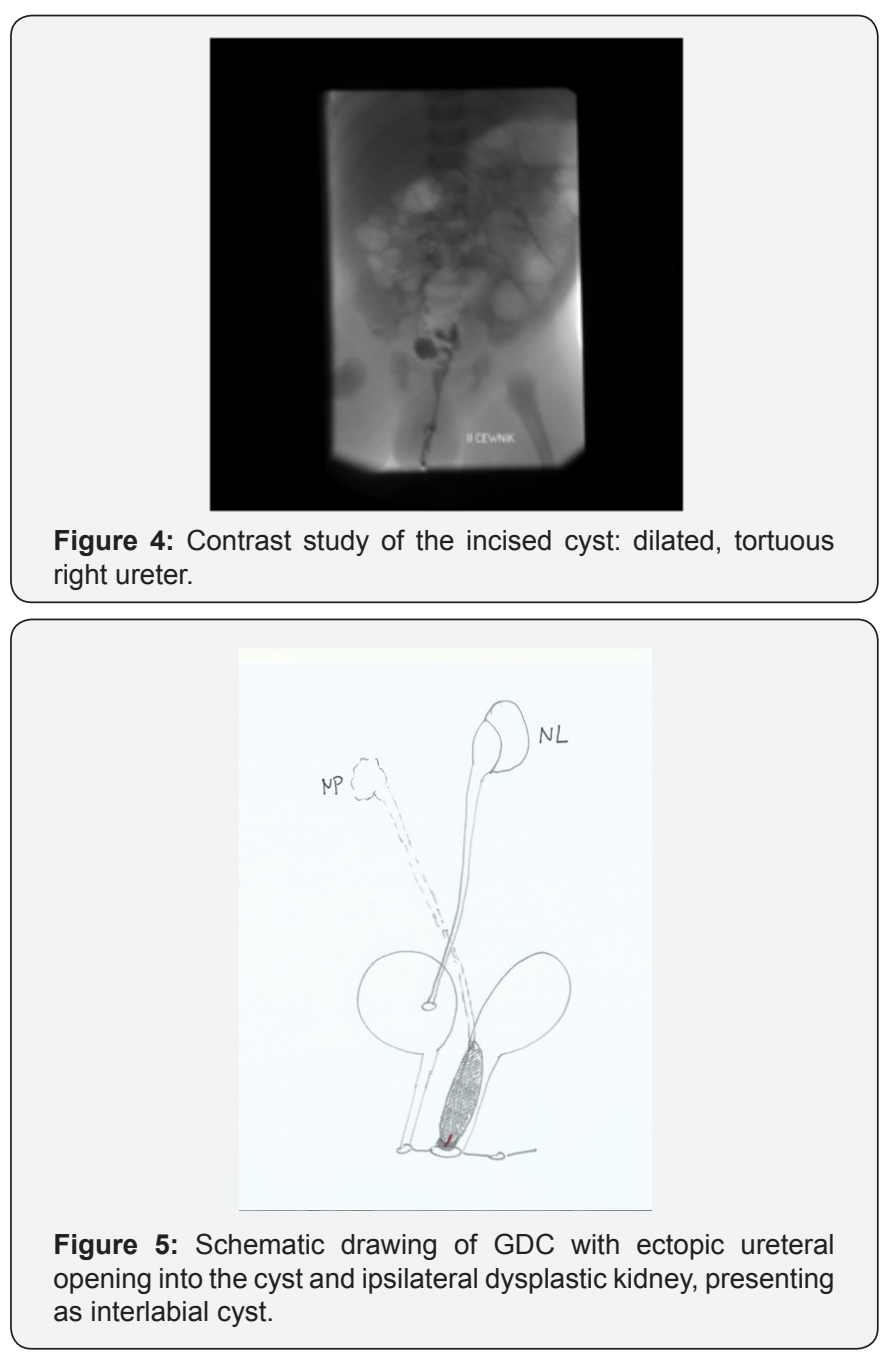

\section{Discussion}

GDC derives from the distal remnants of mesonephric (Wollfian) duct and can be associated with urogenital abnormalities [4]. Persistent GDC with vaginal ectopic ureter and ipsilateral renal agenesis or dysplasia is very rare congenital malformation. This results from cranial displacement of the ureteric bud, together with incomplete incorporation of the distal Wolfian duct into the urogenital sinus and incomplete absorption of this duct into the Müllerian duct [5]. Up to 2007 about 40 cases of this genitourinary anomaly in children were reported in the literature [1-3,6,7]. In 2010 another 9 girls with GDC with unilateral renal agenesis or dysplasia were described [8]. Only on 6 occasions GDC presenting as an introital mass with an ectopic ureter was described in infants, and only twice in newborns [1-3]. One more case of GDC in an infant was described but without concomitant urinary tract anomaly [8].

Probably our case of GDC in newborn causing disturbed micturition due to extrinsic compression of the bladder wall by the cyst is the first one, however, this possibility was mentioned in the literature [6].

Five out of 9 girls described by Japanese authors, aged 3-6 years at the time of GDC detection, complained of intractable urinary incontinence and underwent nephrectomy [9]. Only in one after nephrectomy the leakage stopped completely, the other required intervention on the bladder neck. In 2013 a unique case of 16 year old girl with normal functioning single system ectopic ureter draining into a Gartner's cyst and causing continuous dribbling since birth was published. Laparoscopic reimplantation of the ureter with ligation of its distal stump resulted in complete dryness [10].

Various treatment options are proposed, including marsupialization of the cyts thought the vagina in order to obtain external drainage, cyst un-roofing via the vaginal opening, partial resection of the cyts $[1,2,6-8]$. Removal of the entire cyts generally is not recommended. In case of urinary tract infection/ sepsis or urinary incontinence open nephroureterectomy of the affected side id proposed $[1,8]$, or laparoscopic approach in symptomatic cases [6].

\section{Conclusion}

Our observation suggests that even wide, simple incision of GDC can result in complete resolution of compression caused by large cyst. The diagnosis of GDC should be taken into consideration in an female newborn with vaginal cyst, however, represents diagnostic challenge.

\section{References}

1. Holmes M, Upadhyay V, Pease P (1999) Gartner's duct cyst with unilateral renaldysplasia presenting as an introital mass in a new born. PediatrSurgInt 15(3-4): 277-279.

2. Binsaleh S, Al-Assiri M, Jednak R, El-Sherbiny M (2007) Gartner duct cyst simplified treatment approach. IntUrolNephrol 39(2): 485-487.

3. Rosenfeld DL, Lis E (1993) Gartner's duct cyst with a single vaginal ectopic ureter and associated renal dysplasia or agenesis. J Ultrasound Med 12(12): 775-778.

4. Dwyer PL, Rosamilia A (2006) Congenital urogenital anomalies that are associated with the persistence of Gartner's duct: a review. Am J ObstetGynecol 195(2): 354-359.

5. Currarino G (1982) Single vaginal ectopic ureter and Gartner's duct cyst with ipsilateral renal hypoplasia and dysplasia (or agenesis). J Urol 128(5): 988-993.

6. Castagnetti M, Cimador M, De Grazia E (2008) Diagnostic laparoscopy in a Gartner's duct cyst. J PediatrUrol 4(2): 173-175. 
7. Sheih CP, Li YW, Liao YJ, Huang TS, Kao SP, et al. (1998) Diagnosis the combination of renal dysgenesis, Gartner's duct cyst and ipsilateral Müllerian duct obstruction. J Urol 159(1): 217-221.

8. Shimada K, Matsumoto F, Matsui F, Obara T (2010) Retrovesical cystic lesions in female patients with unilateral renal agenesis or dysplasia. Int J Urol 17(6): 570-578.
9. Ohya T, Tsunoda S, Arii S, Iwai T (2002) Diagnosis and treatment for persistent Gartner Duct Cyst in an infant: a case report. J PediatrSurg 37(4): E4.

10. Prakash J, Singh BP, Sankhwar S, Goel A (2013) Normal functioning single system ectopic ureter draining into a Gartner's cyst: laparoscopic management. BMJ Case Rep pii: bcr2013009563.

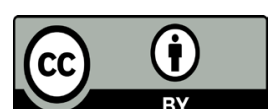

This work is licensed under Creative Commons Attribution 4.0 License DOI: $10.19080 / J O J U N .2017 .3 .555602$

\section{Your next submission with Juniper Publishers will reach you the below assets}

- Quality Editorial service

- Swift Peer Review

- Reprints availability

- E-prints Service

- Manuscript Podcast for convenient understanding

- Global attainment for your research

- Manuscript accessibility in different formats

(Pdf, E-pub, Full Text, Audio)

- Unceasing customer service

Track the below URL for one-step submission https://juniperpublishers.com/online-submission.php 